\title{
Exploring the new policy framework of environmental performance management for shipping: a pilot study
}

\author{
Abu Hasan Rony ${ }^{1} \cdot$ Momoko Kitada $^{1}$ (D) Dimitrios Dalaklis ${ }^{1} \cdot$ Aykut I. Ölçer $^{1}$ • \\ Fabio Ballini ${ }^{1}$
}

Received: 3 September 2018 / Accepted: 7 February 2019 / Published online: 6 March 2019

(C) World Maritime University 2019

\begin{abstract}
Changes in weather patterns are now recorded more and more frequently in various locations of the Earth. Collective action is needed to deal with the challenges of climate change; the maritime industry must contribute its fair share to those activities, aiming to mitigate a risk that can threaten humanity's own existence. On the positive side, both the European Union (EU) and the International Maritime Organization (IMO) have clear ambitions to reduce greenhouse gas $(\mathrm{GHG})$ emissions from ships that are linked to climate change, and two similar albeit separate regimes have been introduced. EU's monitoring, reporting, and verification (MRV) regulation of $\mathrm{CO}_{2}$ emissions has already been influencing shipping activities, since the related data collection has started on the 1 st of January 2018. The second initiative is the IMO's data collection system (DCS), which revolves primarily around fuel consumption; the necessary data collection started on the 1st of January 2019. To support an effective environmental performance management framework for the maritime industry, it is necessary to create a robust database that describes all aspects of energy efficient ship operations, with an emphasis on the inventory of $\mathrm{CO}_{2}$ emitted from ships. The analysis at hand examines the challenges in the relevant data collection scheme, with a particular focus on MRV, considering that the specific regulation is already operationalized. An online survey was conducted among maritime professionals in Singapore and Bangladesh to examine the gap between current energy-related regulations/policies and standing operational practices. The findings address the issues relating to shipping operations and certain compliance, institutional and management matters. They also identify the industry's preparedness for this new policy framework of environmental performance management as well as the impact on existing energy efficiency practices. A very important
\end{abstract}

Momoko Kitada

mk@wmu.se

1 Marine Technology and Maritime Energy Management Research Group (MarEner), World

Maritime University, Fiskehamnsgatan 1, SE-211 18 Malmö, Sweden 
conclusion derived is that the quality of data collected is crucial for the effective management of emissions related to shipping and the associated fuel consumption.

Keywords Environmental performance management $\cdot$ Monitoring, reporting, and verification $(\mathrm{MRV}) \cdot$ Data collection system $(\mathrm{DCS}) \cdot \mathrm{CO}_{2}$ emissions $\cdot$ Data collection and processing

\section{Introduction}

A certain number of important environmental precedents were recorded during the last decade; unfortunately, the vast majority of them are far from desirable. It is indicative that, according to the World Economic Forum (during the whole time period covered by its reporting), 2016 was the first year in which an environmental danger, specifically "failure of climate change mitigation and adaptation", ranked first above weapons of mass destruction, water shortage, and energy resource prices. (World Economic Forum 2016). Worldwide, changes in weather patterns are now recorded more and more frequently; collective action is needed in order to deal effectively with the pressing issue of climate change (Dalaklis et al. 2016).

Studies on climate systems suggest that humans themselves are one of the causes of these climate and weather anomalies (Intergovernmental Panel on Climate Change (IPCC) 2013). Prolonged emissions related to the burning of fossil fuels are causing irreversible change in the climate system, certainly at the regional level-with the Arctic region standing out (Dalaklis and Baxevani 2016; Drewniak et al. 2018) - and with possible global implications. IPCC's fourth assessment report (AR4) states that the period 1983-2012 was the warmest 30-year period in the last 1400 years. The magnitude of damage can only be minimized by stricter control over greenhouse gas (GHG) emissions at a global level. Realizing the adverse impact, various political actors initiated actions to achieve stricter control over carbon dioxide $\left(\mathrm{CO}_{2}\right)$ emissions, leading to the adoption of the "Paris Agreement" under the United Nations (UN). However, the maritime and aviation industries were excluded from the "Paris Agreement" because of their international nature and oversight by specialized UN bodies, namely the International Maritime Organization (IMO) and the International Civil Aviation Organization (ICAO) (IPCC 2013).

Emissions from the maritime industry, from 2007 to 2012, correspond to approximately $2.8 \%$ of the global annual total GHG emissions (IMO 2015). According to the portal for statistics, STATISTA, there are more than 51,400 merchant ships (as of 1 January 2016) operating around the world. These vessels are responsible for consuming an average 350 million tons of fuel oil per year. In a business-as-usual (BAU) scenario, emissions from ships are expected to increase by between 50 and $250 \%$ by 2050 (IMO 2015; Dewan et al. 2018). In another report of interest, the United Nation's (UN) World Population Prospects predict an approximate $30 \%$ increase in the world population by 2050, compared to 2017 figures (UN 2017). This significant rise in the world population will certainly increase the demand for international trade and shipping operations. Interventions related to energy usage and patterns of consumption will be crucial to reduce emissions from ships. 
With the European Union (EU) paying close attention to environmental issues that relate to shipping, EU's regulation 2015/757, dealing with monitoring, reporting, and verification (MRV) of $\mathrm{CO} 2$ emissions in relation to maritime transport, entered into force on the 1st of July 2015. The objective of this regulation, also known as the MRV regulation, is to gain a better understanding of fuel consumption and $\mathrm{CO} 2$ emissions related to shipping activities within Europe. ${ }^{1}$ Briefly, irrespective of the vessel's flag, the regulation under discussion applies to ships greater than 5000 gross tonnage (GT) undertaking one or more commercial voyages into, out of, or between European Economic Area (EEA) ports. The MRV regulation requires per-voyage and annual monitoring of $\mathrm{CO}_{2}$ emissions; other parameters are also included, such as quantities of cargo carried and miles traveled. Furthermore, the annual disclosure of aggregated data on a ship-by-ship basis is required (Nikitakos et al. 2018).

There are also developments in a similar direction by the IMO. Paving the way towards an energy-efficient and sustainable maritime industry, the IMO adopted two regimes in 2009, namely, the Ship Energy Efficiency Management Plan (SEEMP) and Energy Efficiency Design Index (EEDI), which entered into force on the 1st of January 2013. These instruments were introduced to facilitate vessels engaged in maritime transport to adopt energy efficient, sustainable, and technologically improved policies and measures (Ölçer 2018). The IMO has further pushed forward efforts to reduce GHG emissions from ships: IMO's data collection system (IMO DCS) on fuel consumption is already established, with the relevant data collection starting on the 1st of January 2019. Both EU's MRV and IMO's DCS requirements are mandatory and are intended to be the first steps in a process to collect and analyze emission data related to the shipping industry (DNV-GL 2018). A comparison of the relevant implementation schedule of these two very influential policy tools is presented in Table 1 .

While the EU data collecting and reporting scheme has its focus on $\mathrm{CO} 2$ emissions from shipping activities to, from, and within the EU area, the relevant scheme by IMO covers emissions from global shipping. More importantly, it is essential to highlight that whether, how and when the two regimes will converge has not yet been decided. In Table 2, the main differences in the implementation approaches of the two regimes are presented; the issue of how the collected data is treated in terms of confidentiality clearly stands out.

Since monitoring/reporting of emissions related to shipping is a rather recently introduced regime, there are only a handful of academic research efforts examining its influence upon the maritime industry (see for example, Zaman et al. 2017). The focus of the analysis at hand is MRV, considering that the specific regulation is already operationalized; its main aim is to address the challenges in the relevant data collection scheme and also highlight possible implications on shipping activities and daily operational procedures. After this introductory section, the overall framework of maritime policies related to energy management is briefly presented, along with a short discussion of their level of effectiveness. Subsequently, the data gathered via a relevant questionnaire completed by maritime professionals in Singapore and Bangladesh in

\footnotetext{
${ }^{1}$ After its initial inception, the MRV framework is under continuous improvement. Delegated regulation 2016/2072 has amended that first MRV regulation; it must also be read in conjunction with delegated regulation 2016/2071 and implementing regulations 2016/1927 \& 2016/1928.
} 
Table 1 EU MRV and IMO DCS timeline of implementation (prepared by the authors as an adaptation from DNV-GL 2018).

\begin{tabular}{|c|c|c|}
\hline Timeline & EU MRV & IMO DCS \\
\hline 31 August 2017 & $\begin{array}{l}\text { Monitoring plans submitted } \\
\text { to accredited verifier }\end{array}$ & \\
\hline 1 January-31 December 2018 & First reporting period & \\
\hline 1 March 2018 & & $\begin{array}{l}\text { Chapter } 4 \text { of the International } \\
\text { Convention for the Prevention } \\
\text { of Pollution from Ships (MARPOL) } \\
\text { Annex VI enters into force }\end{array}$ \\
\hline 31 December 2018 & & $\begin{array}{l}\text { SEEMP part II assessed for compliance } \\
\text { by flag state/RO (recognized } \\
\text { organization). CoC (certificate of } \\
\text { compliance) issued }\end{array}$ \\
\hline 1 January-31 December 2019 & & First reporting period \\
\hline 30 April 2019 & Verified annual emission report & \\
\hline 30 June 2019 & Publication of data by EC & \\
\hline 31 January 2020 and yearly & & $\begin{array}{l}\text { Companies to create annual FOC } \\
\text { (fuel oil consumption) reports and } \\
\text { submit to flag state/RO }\end{array}$ \\
\hline 31 May 2020 and yearly & & $\begin{array}{l}\text { Flag state/RO to issue SoC (statement } \\
\text { of compliance) on the FOC report }\end{array}$ \\
\hline
\end{tabular}

relation to the MRV regulation is analyzed to extract the most important findings. A discussion of barriers identified is also included before the concluding section.

\section{Maritime policies related to energy management}

A number of energy policy developments have been observed within the maritime industry over the last decade. The IMO's second and third GHG studies $(2009 ; 2014)$ provide a detailed picture of emissions related to shipping, as well as the trends and trajectories for future scenarios. At the IMO level, the Marine Environment Protection Committee (MEPC) is responsible for setting out the regulatory directions and procedures for GHG emission reductions. Strong indicative examples include Annex VI of the International Convention for the Prevention of Pollution from Ships (MARPOL), 1973 as modified by the Protocol of 1978, in particular in its regulation 22A for data collection system; regulation 22A amendments (Res.MEPC278(70)); guidelines of calculation of EEDI (Res. MEPC.245(66)); EEOI (MEPC.1/Circ.684, 2009); and SEEMP (Res. MEPC282(70)). In the 72nd MEPC meeting in April 2018, various resolutions and guidelines were adopted that relate to fuel consumption and $\mathrm{CO} 2$ emissions. For example, the member states discussed the key environmental issues for the global shipping industry with special focus on the adoption of an initial strategy for the reduction of GHG emissions from ships, including also the sulfur 2020 limit, heavy fuel oil (HFO) use in the Arctic, the Ballast Water Management (BWM) Convention, marine litter, and biofouling. Before moving in a different direction, it is 
Table 2 EU-MRV and IMO's DCS Comparison (prepared by the authors, as an adaptation from DNV-GL 2018).

\begin{tabular}{|c|c|c|}
\hline & EU MRV & IMO's DCS \\
\hline Monitoring plan: & $\begin{array}{l}\text {-Separate document describing the } \\
\text { methodology for data collection } \\
\text { and reporting } \\
\text {-Pre-defined format published by } \\
\text { EC and subject to verification by } \\
\text { an independent accredited verifier } \\
\text {-Deadline for submission of monitoring } \\
\text { plan was } 31 \text { Aug. } 2017\end{array}$ & $\begin{array}{l}\text {-Data collection and reporting } \\
\text { methodology shall be } \\
\text { described in a SEEMP, part II } \\
\text {-Conformation of compliance } \\
\text { by flag state/RO } \\
\text {-Deadline for submission of SEEMP } \\
\text { part II is } 31 \text { Dec. } 2018\end{array}$ \\
\hline Reporting to: & $\begin{array}{l}\text { European Commission: } \\
\text {-Company will report annual emissions } \\
\text { to the EMSA's data base } \\
\text { ("THETIS MRV") } \\
\text {-Annual report to be verified by an } \\
\text { accredited verifier }\end{array}$ & $\begin{array}{l}\text { Flag State: } \\
\text {-Annual emission report to be } \\
\text { verified by Flag State/RO } \\
\text {-Flag State (or RO) reports to } \\
\text { IMO data base }\end{array}$ \\
\hline Reporting details: & $\begin{array}{l}\text {-Log abstract reports for: voyages to } \\
\text { and from EU ports; voyages between } \\
\text { EU ports and at berth } \\
\text {-The reports should contain: fuel } \\
\text { consumption; cargo carried; } \\
\text { distance; time; transport work. } \\
\text {-Fuel balance report containing bunker } \\
\text { delivery notes and remaining } \\
\text { on-board reports }\end{array}$ & $\begin{array}{l}\text {-Log abstract reports for all voyages } \\
\text {-Containing: fuel consumption; } \\
\text { distance; and time } \\
\text {-Fuel balance report containing } \\
\text { bunker delivery notes and } \\
\text { remaining on-board reports }\end{array}$ \\
\hline Disclosure: & Data publicly available & Ship data will be kept confidential \\
\hline
\end{tabular}

also useful to highlight here that IMO's GHG strategy describes the minimum ambition of reducing $\mathrm{CO}_{2}$ emissions by $50 \%$ by 2050, compared to 2008 levels, while the maximum possible ambition renders zero emission.

\subsection{Development of maritime energy policies}

\subsubsection{SEEMP/EEDI/EEOI}

The Ship Energy Efficiency Management Plan (SEEMP) sets the ground for IMO's DCS and the smooth implementation of the latter on board ships. Both processes (SEEMP and IMO's DCS) require continuous monitoring of energy consumption. The IMO's DCS regulation allocates responsibility for verifying the monitoring plan and ensuring robust data is reported to the IMO's fuel consumption database for global stock. Additionally, the Energy Efficiency Operational Indicator (EEOI) is a monitoring tool for managing ship and fleet efficiency performance over time (IMO 2009). The various elements of data required for the calculation of EEOI are similarly applicable to IMO's DCS data collection process. In the case of SEEMP, the EEOI is used as the primary monitoring tool where quantitative measurements for EEOI calculations are necessary, according to regulation 22A of MARPOL, Annex VI. 


\subsubsection{IMO's DCS}

IMO's DCS was proposed at the 70th MEPC meeting in October 2016 under the notion of further promoting the issue of energy efficiency within the maritime transport industry. This was regarded as a substantial step towards achieving a better environmental footprint for shipping and making other energy efficiency measures more transparent and effective. The goal of IMO's DCS is to establish a global fuel consumption database; this requires a robust/continuous flow of data and the establishment of an undisturbed link between all the stakeholders involved in the process. Therefore, maintaining the quality of associated data and the effective participation of all stakeholders are clearly matters of concern. Figure 1 presents the flow of data between the responsible parties in IMO's DCS regulation. This figure reflects the other previously mentioned concepts introduced by the IMO with the aim of improving energy efficiency of vessels, such as SEEMP, the mandatory requirement of EEDI for new ships, the EEOI for existing ships, and, as already highlighted, the fuel consumption data collection system for ships of GT 5000 and over.

\subsubsection{EU's MRV}

In the case of the EU, all transport modes-including the maritime sector-are included within an initiative focusing on climate change, according to which emissions are measured and controlled (to a certain extent) under mandatory regulations and participation. As such, the integration of MRV into EU's policy portfolio was the primary reason for this adaptation: to reduce emissions from the maritime industry. In the EU, maritime transportation volume increased by $48 \%$ between 1990 and 2007 (EUR-Lex n.d.). EU regulation 2015/757 considers that EEDI, EEOI, and SEEMP alone may not be sufficient to reduce GHG emissions; therefore, it is essential to adopt a more stringent policy framework. In that regulation, the introduction of MRV is justified as a benchmarking tool for maritime energy efficiency management. This regulation also sets a target for 2030 to reduce GHG pollution from domestic sources by at least $40 \%$, compared to the 1990 level. The EU expects that the implementation of MRV will reduce ship emissions by $2 \%$ within its extended region, compared to the BAU scenario in the future (European Commission 2017).

Under the EU's MRV system, ships over 5000 GT arriving at, within, or departing from an EU port are required to collect data both annually and on a per-voyage basis

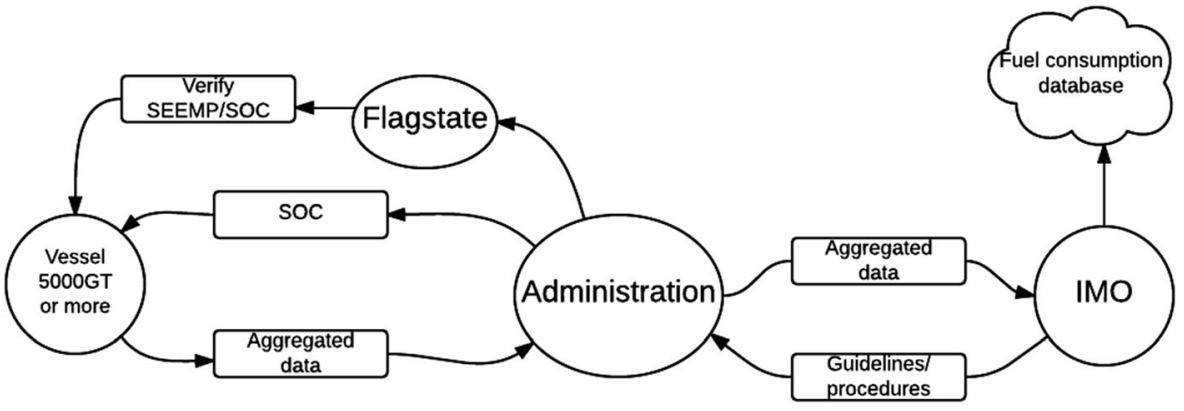

Fig. 1 IMO DCS data flow (source: prepared by the authors as an adaptation from res. MEPC.278(70) 
and to report $\mathrm{CO}_{2}$ emissions to the Commission. This translates into the fact that the MRV framework requires various stakeholders to simultaneously participate in the process. Additionally, as shown in Table 3, EU's MRV follows a staged approach to future emission abatement techniques, but the successful implementation will be subject to a number of barriers and benefits.

\subsection{Comparison of SEEMP, IMO's DCS, and EU's MRV sources of emission}

A comparison among the SEEMP, IMO's DCS, and EU's MRV is presented in Table 4 , in terms of sources of emission related to fuel consumption. Considering that it is necessary to establish an internationally recognized method of quantitative measurement of EEOI for a vessel, it can be considered as the primary step for a vessel's energy efficiency monitoring (MEPC.213(63): SEEMP guidelines). The tools, concepts, and methods of monitoring the energy efficiency data must be determined at the planning stage and mentioned in each vessel's SEEMP (Korean Register of Shipping, n.d.). The MRV framework can be used for good energy governance; without a rigid data collecting and reporting scheme, the various energy efficiency initiatives already in place may not be as effective as envisioned during their inception.

\subsection{MRV implementation}

Shipping companies, in order to maintain their licenses to operate in Europe, will need to comply with the MRV regulation; the specific framework is expected to contribute to reducing maritime emissions related to seagoing vessels, although additional measures will be needed. According to the 61st MEPC information paper (IMO 2010), the expert group submitted a feasibility study on reducing GHG emission from ships. The study included various market-based measures (MBMs) exercised by various member states, such as GHG Fund for ships, leveraged incentive scheme (part of GHG fund goes to good ships), port state levy (award to green and efficient ships), ship efficiency and

Table 3 Staged approach of EU MRV, (source: prepared by the authors, as an adaptation from regulation (EU) 2015/757).

\begin{tabular}{|c|c|c|c|}
\hline Stages & & Barriers & Benefits \\
\hline First stage & $\begin{array}{l}\text { Implementation } \\
\text { of MRV }\end{array}$ & $\begin{array}{l}\text {-Split incentives } \\
\text {-Lack of information } \\
\text { about technology } \\
\text {-Lack of information } \\
\text { about ship } \\
\text {-Reliable information } \\
\text { about ship's fuel } \\
\text { efficiency }\end{array}$ & $\begin{array}{l}2 \% \text { reduction of shipping emission } \\
\text { compared to BAU } \\
\text { Cost reduction of Euro } 2 \text { billion by } 2030 \\
\text { Reliable information about ships' } \\
\text { efficiency and fuel consumption } \\
\text { Removal of market barrier } \\
\text { Help international data collection system } \\
\text { to be easily implemented }\end{array}$ \\
\hline Second stage & $\begin{array}{c}\text { Putting a price } \\
\text { on shipping } \\
\text { emissions }\end{array}$ & $\begin{array}{l}\text {-International nature } \\
\text { of transport }\end{array}$ & Reduce transport cost \\
\hline
\end{tabular}


Table 4 Emission sources under EEOI, IMO DCS, and EU-MRV system (prepared by the authors, as an adaptation from guidelines MEPC.1/Cir684 for calculation of EEOI, IMO resolution MEPC 278(70), and EU regulation $757 / 2015$.

\begin{tabular}{|l|c|c|c|}
\hline \multicolumn{1}{|c|}{ Source of emission } & EU-MRV & IMO-DCS & IMO-SEEMP (EEOI) \\
\hline Main Engines & $\square$ & $\square \square$ & $\square \square$ \\
\hline Auxiliary Engines & $\square$ & $\nabla \square$ & $\square \square$ \\
\hline Boilers & $\square$ & $\square \square$ & $\square \square$ \\
\hline Gas Turbines & $\square$ & $\square \square$ & $\square \square$ \\
\hline Inert Gas Generators & $\square$ & $\nabla \square$ & $\mathbf{X}$ \\
\hline Incinerator & $\square$ & $\mathbf{X}$ & $\square$ \\
\hline
\end{tabular}

credit trading, vessel efficiency system, global emissions trading scheme for international shipping, and emissions trading scheme. Some of these proposals could be effectively enforced when emissions from maritime transport are appropriately inventoried and under a continuous monitoring regime. The stringent regulations and economic incentives for energy efficiency are the driving forces that will influence a company to invest in GHG abatement technologies and achieve significant GHG reductions in maritime transport (IMO 2010). These MBMs require the benchmarking of emissions from ships as well as from the entire maritime transport sector based on robust data. However, challenges are anticipated in the MRV implementation process.

\subsection{Challenges in MRV}

Developing a monitoring plan verified by an accredited verifier for MRV purposes is vital. This requires a series of assessments involving a complete data collection, storage, and transmission process. A monitoring plan is considered to be the backbone of the MRV framework and should be reviewed regularly, at least once per year (EURLex n.d.). In the EU's MRV, several procedures must be included in the monitoring plan, such as measuring fuel uplift and fuel in the bunker tanks; ensuring the uncertainty of fuel measurement to be consistent with the requirement in the regulation and even the fuel suppliers' accuracy standard; recording and determining the distance traveled, cargo carried, and time spent at sea; and detecting surrogate data and eliminating data gaps (EUR-Lex n.d.). The appropriate handling of such extensive data could be a very challenging task (Nikitakos et al. 2018), and the type of "data-mining" tools to be used is another relevant question that remains pending.

\section{Method of research}

A survey questionnaire was developed to serve the purposes of this explorative study. Dillman (2007) points out that a survey questionnaire describes more than just a general inquiry. The attitude, attributes, behavior, and belief of each respondent can be determined by the sample of survey questions, which also serves as a tool for the surveyor 
(Dillman 2007). Therefore, answers provided by the use of a questionnaire can help to diagnose or reach a decision on the basis of the outcome. Other methods were unsuitable for this particular study, which aimed to reach a wide range of participants, including ship managers, marine engineers, and deck officers who rarely work regular hours and are difficult to contact directly. Hence, the survey was designed in an online format, allowing more informants to participate.

The online survey began with a consent form, requesting all participants to confirm that they fully understand the ethical issues, such as confidentiality and voluntary participation, and agree to data being used for research and disseminated. The principal motivation of the survey was to reveal the potential barriers and industry's standpoint with regard to the implementation of the upcoming shipping framework of environmental performance management for shipping, created by both EU and IMO. For this purpose, the survey was divided into five sections: A: general questions, B: policy perspective, $\mathrm{C}$ : technological standpoint, D: human element, and E: ensuring quality of data. A sample survey can be found in Appendix 1. The participants for this exploratory study were maritime professionals in Singapore and Bangladesh where one of the authors used to work as a seafarer. The original research idea was to conduct a pilot study on the challenges of environmental performance management for the shipping sector in non-EU countries. Environmental performance management led by EU and IMO has a significant impact on the countries outside Europe. Understanding the implications of such shipping management from the examples of Singapore and Bangladesh is considered to be a good starting point to examine the current challenges.

The online survey was administered between June and July 2017 and 74 responses were collected. Among all respondents, $90 \%$ are male and the rest $(10 \%)$ are female with diverse maritime backgrounds, such as navigating officers $(n=13,17.81 \%)$, ship's engineers $(n=32,43.84 \%)$, maritime administrator $(n=6,8.22 \%)$, ship managers $(n=11,15.07 \%)$, port officials $(n=3$, $4.11 \%)$, maritime education and training providers $(n=2,2.74 \%)$, classification society surveyors $(n=2,2.74 \%)$, pilots $(n=1,1.37 \%)$, marine surveyors $(n=1$, $1.37 \%)$, flag administrators $(n=1,1.37 \%)$, and others. The demographic profile of the participants indicates that all participants are in the middle or later stages of their careers, from which a degree of reliability, validity, and credibility of responses is reasonably guaranteed. None of the participants are below 25 years of age; $50 \%$ are between 35 and 45 years old; more than $66 \%$ are over 35 ; and $16 \%$ are over 45 years of age. Moreover, it was evident that many participants possess high educational qualifications as $40 \%$ hold masters' degrees or above, $47 \%$ bachelor's degrees, and the rest were either master mariner or certificate of competency (class 1) holders.

The collected data was thematically analyzed, and barriers to the implementation of maritime policy related to energy were identified. The identification of barriers was a complex process which required a wide range of knowledge that spans from regulatory requirements to vessel data collection systems; it also required strong familiarity with vessel operators' practices. Therefore, some other barriers aside from policy-related ones were examined by employing a holistic approach. 


\section{Results}

The results of the online survey data analysis are presented in two different parts: the first discusses the "impact of MRV on maritime energy policies" and the second examines the issue of "data quality in MRV implementation".

\subsection{Impact of MRV on maritime energy policies}

According to the survey, $73 \%(n=54)$ of the respondents held the view that the introduction of MRV will positively affect SEEMP to a great extent and also improve energy efficiency on board ships. Over 24\% $(n=18)$ put forward that the MRV will have a minor positive impact on the SEEMP or the issue of "energy efficiency" as a whole. No one identified a negative impact of MRV on SEEMP. As demonstrated via Fig. 2, there is a positive mindset/expectation in relation to MRV. From a behaviorist perspective, the trust that maritime professionals have in this new maritime energy framework could help the smooth implementation of MRV. MRV is highly expected to support and enhance the ship energy efficiency process and contribute to "greener" policy making.

Another aspect measured was the impact of MRV on daily shipping operations. The International Organization for Standardization (ISO) is a global organization that sets standards for various disciplines. Among others, ISO 9001, ISO 14001, and ISO 50001 are important for shipping companies to operate their maritime businesses reputably. Today, many shipping companies subscribe to these ISO standards as part of their corporate social responsibility (CSR) (Ölçer and Ballini 2018). Any company subscribing to these standards will have a better basis on which to put a system in place for maritime energy policies and face less hindrance to implementing MRV. Figure 3 presents the

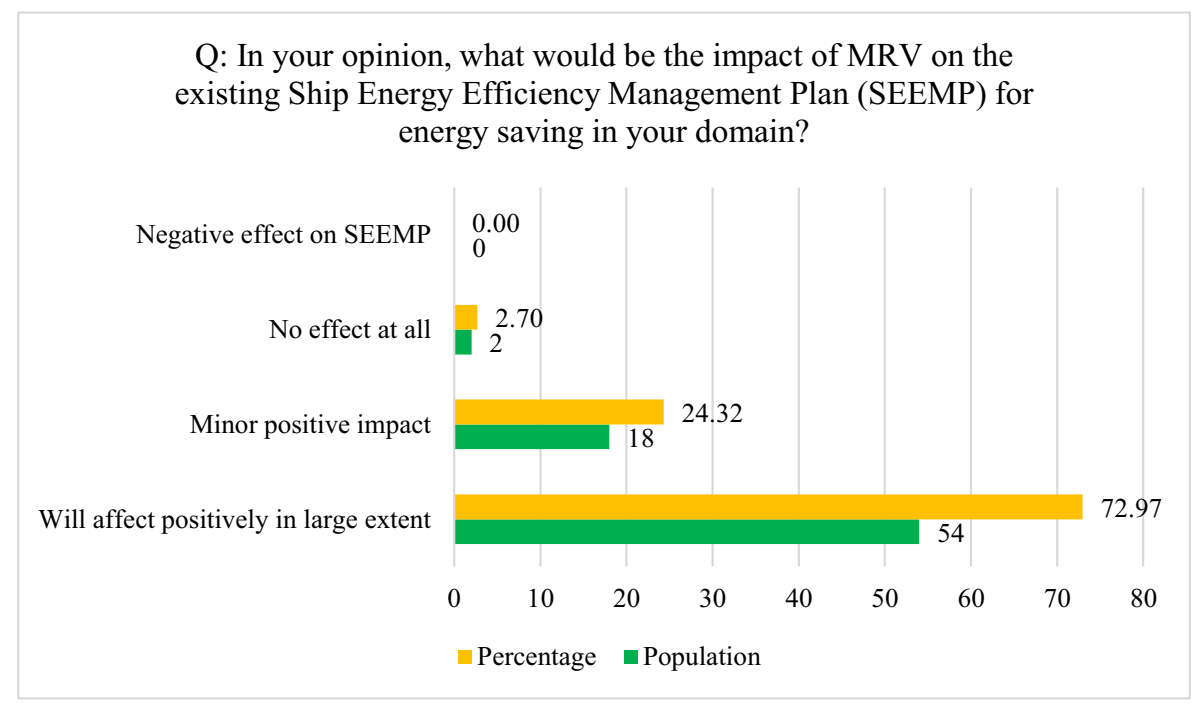

Fig. 2 Impact of MRV on SEEMP 


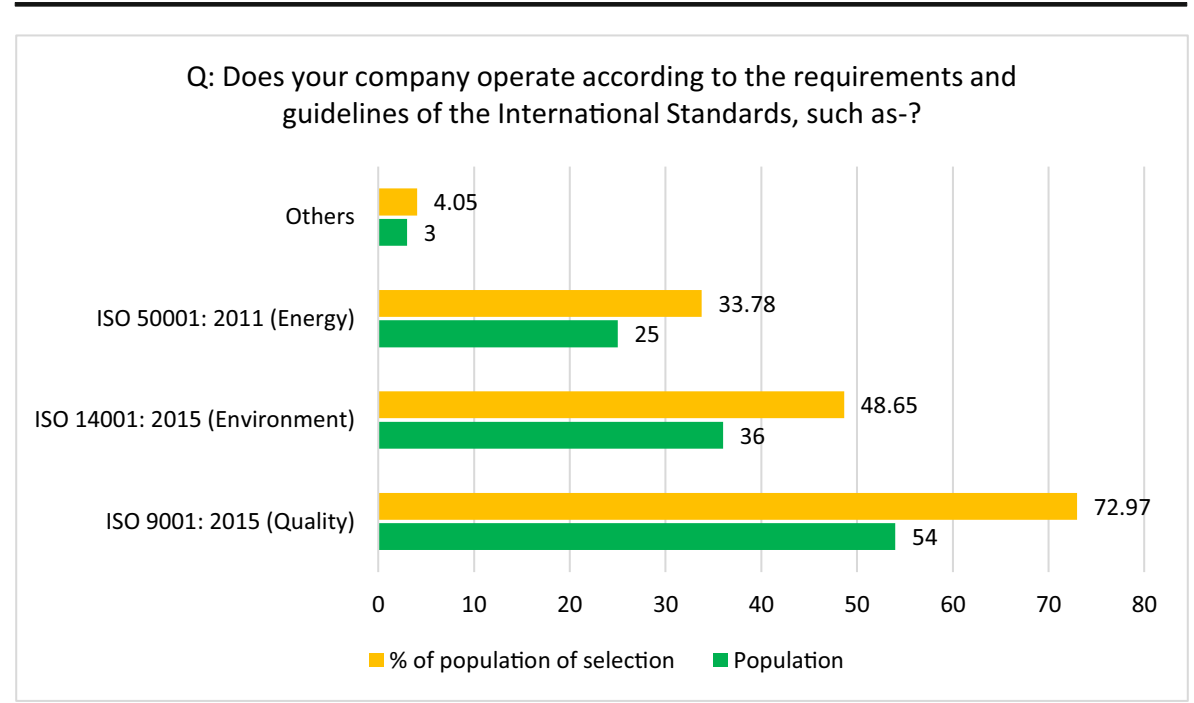

Fig. 3 Use of international standard in a company.

number/percentage of ISO subscription identified via the survey. ISO 9001:2015 concerning company quality management systems was the most selected by the participants $(73 \%, n=54)$. Compliance with ISO 9001:2015 indicates that these organizations are able to provide their customers with quality services (ISO 2017).

About $49 \%(n=36)$ of the respondents' organizations meet the ISO 14001:2015 (Environmental Management) standard; the organizations' activities are monitored and controlled, and environmental impacts are minimized by complying with this standard. Considering available energy management system standards, ISO 50001:2011 is still making its way into the industry as $34 \%$ $(n=25)$ of respondents' organizations are in compliance. Among those ISO standards, ISO 50001 requires organizations to monitor, measure, and analyze their energy performance at planned intervals (ISO 2017), which could be a perfect platform for smooth implementation of MRV. The lack of ISO 50001 subscription means that an energy management system will still need to be adopted by a large proportion of shipping companies. Other participants, whose jobs included dealing with IMO regulations, such as the International Safety Management (ISM) Code, pointed out that none of these international standards were followed; they constituted about $4 \%(n=3)$ of the sample population. It is a small number, but still disappointing, considering that energy management and efficiency should not fall behind other important goals of the maritime industry, such as safety, security, protecting the marine environment, and ensuring occupational health.

To more closely examine the focus on energy efficiency at the institutional level, Fig. 4 summarizes how "energy efficiency" is dealt with by the respective organizations. Approximately, 55\% $(n=41)$ of the respondents stated that 


\section{Q: Is Energy Efficiency included in any of the followings in your company?}

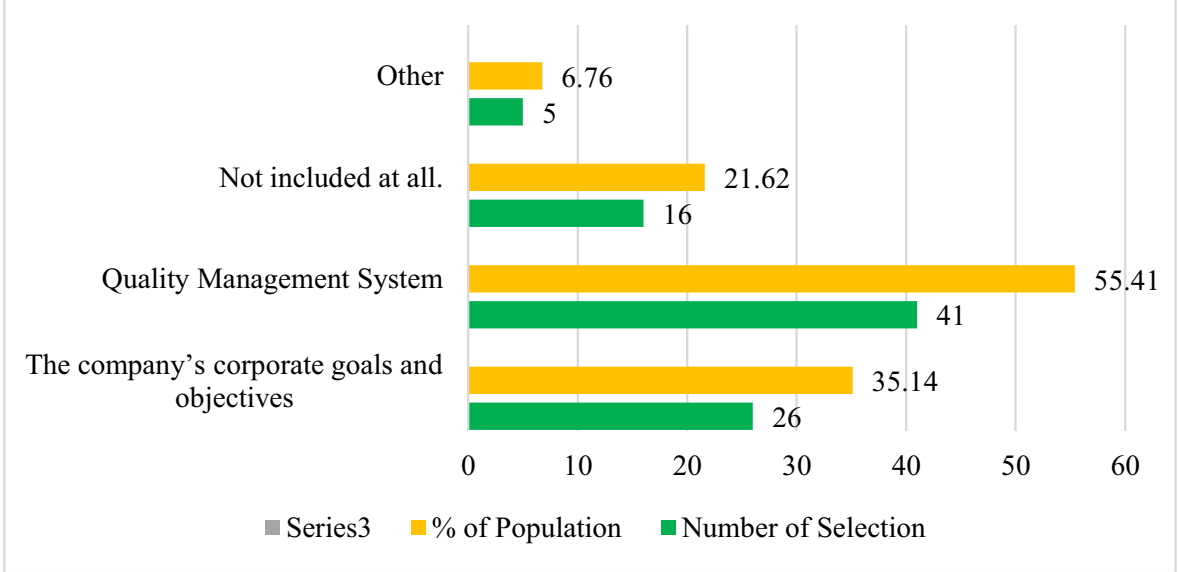

Fig. 4 Inclusion of energy efficiency measures

energy efficiency is included in their quality management systems. A total of $35 \%(n=26)$ of the respondents' organizations have incorporated energy efficiency in their corporate goals and objectives. Approximately, 7\% $(n=5)$ of the participants mentioned that energy efficiency measures (i.e., SEEMP) exist in their organizations and recognized them as being cost effective. However, 22\% $(n=16)$ of the participants answered that energy efficiency is not included in their organization in any type/form. It is important to understand why some organizations are falling so far behind the current trends of maritime energy management; this fact also indicates that there is a gap among the shipping companies in terms of the implementation of maritime energy policies.

\subsection{Data quality in the MRV implementation}

An accurate and reliable source of data is the foundation for an effective MRV framework. Errors in the instruments of the MRV can be considered as important barriers to its effective implementation. It is indicative that errors in the fuel consumption monitoring equipment, such as fuel tank-measuring devices, flowmeters, and exhaust gas outflow-measuring devices can be eliminated by the integration of new monitoring technologies that ensure high precision. However, it is necessary to highlight that when selecting and improving a monitoring methodology, the improvements from greater accuracy shall be balanced against the additional costs. Providing another additional example of room for improvement, existing errors within the banker delivery note (BDN) and short delivery of the bunker could be rectified by appropriate measures such as better regulatory compliance and introduction of various technological solutions. 


\subsubsection{Data robustness}

Maintaining data robustness, including the accuracy of data, is the most important factor in the MRV framework. However, identifying and eliminating data errors are major concerns for the effective implementation of MRV. The chosen monitoring method must be robust enough to ensure that data gaps are minimized and errors/ omissions are avoided.

Table 5 summarizes the results pertaining to data inaccuracy. Fifty percent $(n=37)$ of the participants responded that the most important cause for data inaccuracy could be associated with human errors in data collection and interpretation. This factor is followed by lack of correct procedure $(27 \%, n=20)$. Only $9 \%(n=7)$ identified errors in conjunction with the measuring devices themselves as the main contributor to data inaccuracy during the data collection. Approximately, $11 \%(n=8)$ of the respondents agreed that all of the above reasons included in the relevant question could be responsible for creating inaccuracies in the collected data. If two answers are combined (lack of correct procedure $(27 \%)$ and human error $(50 \%))$, a total of $77 \%(n=57)$ is associated with the domain of the human element. This issue should be further studied in future research that connects the topics of "human element" and "maritime energy management” (Kitada and Ölçer 2015).

\subsubsection{Issues with manual data collection}

Daily fuel consumption of different types of machinery on board ships is transmitted to the head office via relevant electronic forms. In case there is manual reading and entry of data into the relevant system of decision support, there is a waste of effort and opportunities for error or misreporting. Additionally, addressing uncertainty, maintaining reliability, and reducing noise in data servicing MRV purposes is important. Robustness of the MRV framework depends on system integrity and elimination of any existing data gaps during the exchange of relevant information. Misreporting is a noteworthy concern, considering that it could affect a database on a large scale. Figure 5 summarizes the views about how misreporting could occur. About 69\% $(n=51)$ of the participants acknowledged that the main cause for misreporting or wrong entry could be human error or lack of knowledge about the procedure for data entry.

Table 5 Factors for data inaccuracy

\begin{tabular}{lcc}
\hline Factors for data inaccuracy & Population & Percentage \\
\hline Error within the measuring device & 7 & 9.46 \\
Human error in collection and interpretation & 37 & 50.00 \\
Lack of correct procedure & 20 & 27.03 \\
Other & 2 & 2.70 \\
All of above & 8 & 10.81 \\
\hline
\end{tabular}




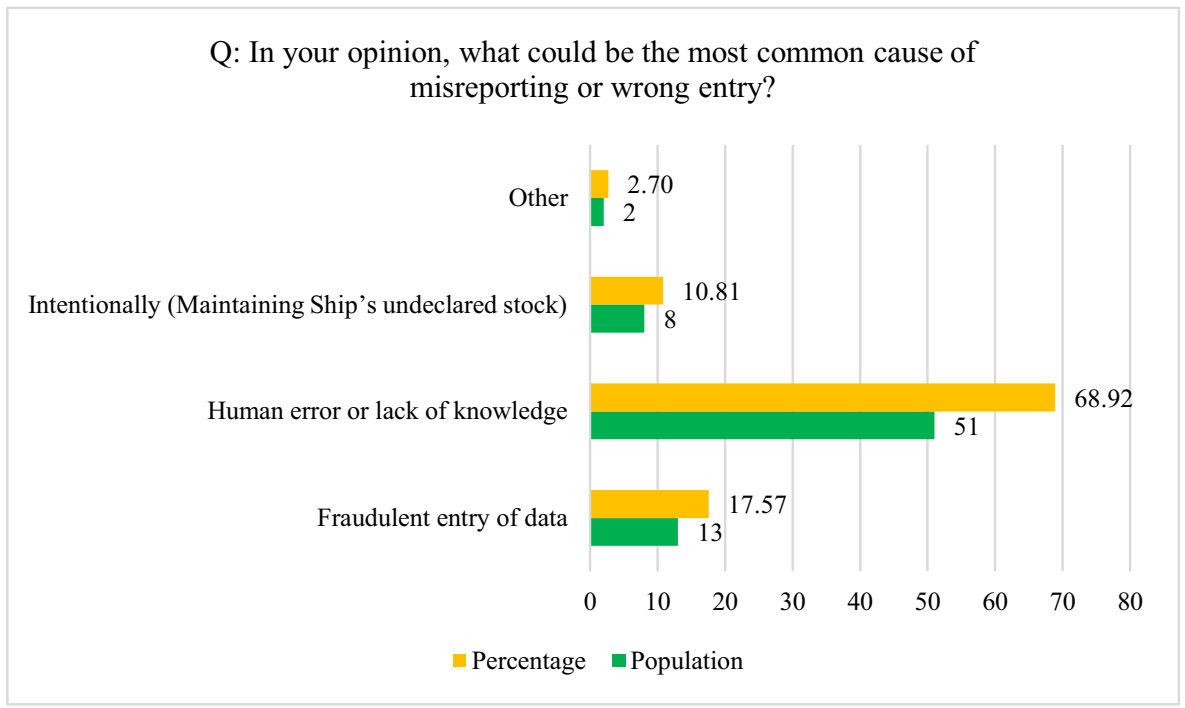

Fig. 5 Cause for misreporting

Of specific concern is the finding that approximately $29 \% \quad(n=21)$ of the participants pointed towards intentional misreporting, including $11 \% \quad(n=8)$ citing intentionally maintaining ship's undeclared stock and 18\% $(n=13)$ citing fraudulent entry of data. This brings the issue of "data integrity" to the forefront.

Technically speaking, there are various modern data management tools available on ships. The online survey also included a question about the types of information technology (IT) systems used on board for data collection, maintenance, storage, and interpretation. The use of a computerized maintenance management system (CMMS) on board facilitates, apart from carrying out sequential maintenance, the recording and transmission of data that fully describes the ship's operation. These systems can provide the backbone for proper implementation of MRV. According to the survey, 54\% $(n=40)$ of the participants noted that their organizations subscribed to CMMS of different kinds, while 28\% $(n=21)$ did not know and approximately 10\% $(n=7)$ did not subscribe to any CMMS (Fig. 6). In summary, a CMMS could be used to transfer data towards the company's head office, as well as any other interested party in the loop of MRV. If the company wishes to integrate the automated data collection system or a common platform for multiple users, it can be better achieved by the CMMS.

\subsubsection{Issues with data collection process}

According to EU regulation 2015/757 and a similar document by IMO (Appendix IX, in res. MEPC.278(70)), the company shall define the procedure for 
Q: What type of IT system is used for maintenance and data collection, storage and interpretation on your ships?

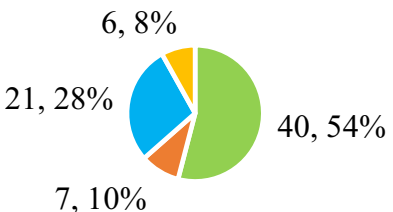

- CMMS (Computerized Maintenance Management System, i.e.; ABS-NS, ADONIS, and etc.)

- Not subscribing to any

- Not known

ఐ Other

Fig. 6 Type of IT system used

data collection and identify methods for detecting surrogate data and eliminating gaps. As shown in Fig. 7, 70\% $(n=52)$ of the participants stated that their organizations have identified potential problems with data collection and transformation, and necessary steps have been taken to improve the quality of data. This shows a firm commitment towards the improvement of data quality by the companies where the participants are working. One of them even suggested that

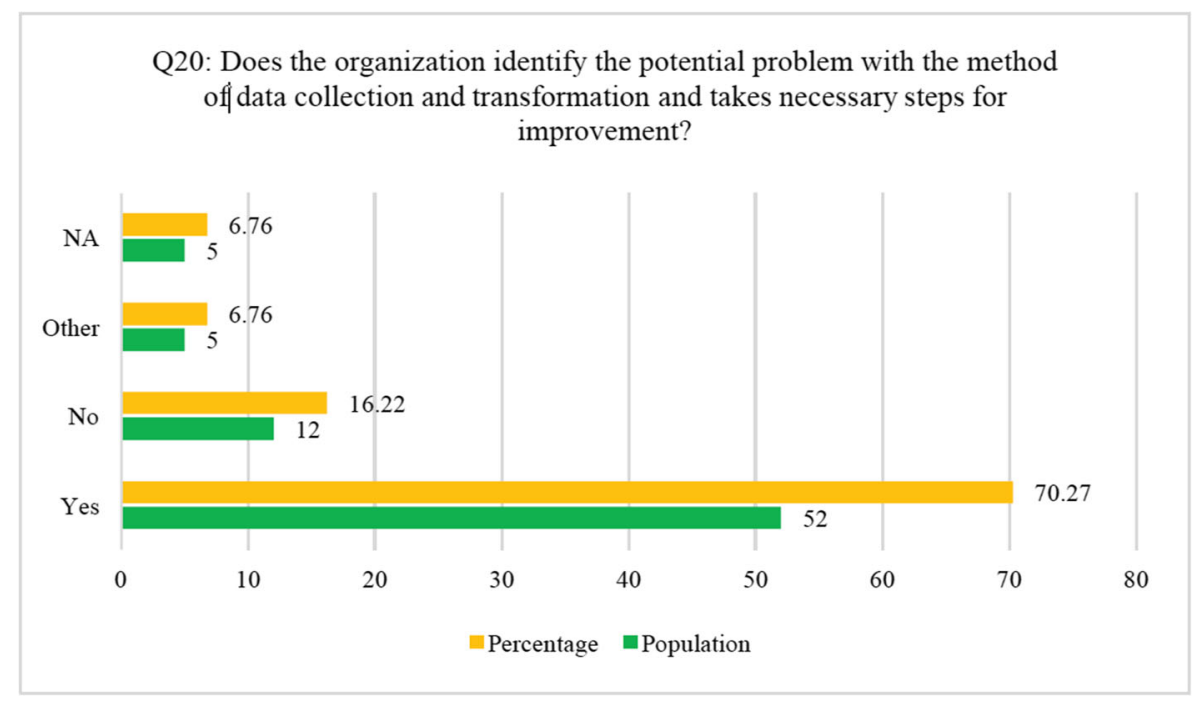

Fig. 7 Problem associated with data collection 
once new regulations are put in place, more problems related to data quality would surface. Rather worrisome is the fact that over $16 \%(n=12)$ of the participants responded that no relevant assessment has been carried out yet. For a high level of compliance to this new framework of environmental performance management for shipping, a thorough assessment should be carried out and then any identified shortcomings need to be vigorously addressed.

\section{Discussion}

Various research efforts identify barriers to maritime energy management, from technical to operational, from behavioral to financial, and from managerial to complexity views of categorizing them (Acciaro et al. 2013; Kitada and Ölçer 2015; Ölçer et al. 2018). In the analysis at hand, the focus revolved around the quality of data that will serve the EU MRV regulation. The survey results appeared to show concerns in terms of the readiness of shipping companies' policies for environmental performance management as well as data quality in MRV implementation. This highlights the role of shipping companies in the successful environmental performance management process. It is a commonly shared knowledge that vessels engaged in maritime transport have an impact on the environment, mainly because of their reliance on internal combustion engines and their related emissions; hence, the maritime industry should make an effort to mitigate the impact of climate change. The specific regulatory framework is the first step of a staged approach for the inclusion of maritime transport's emissions into the European framework of greenhouse gas reduction, alongside all other modes of transport. The overall strategy consists of three consecutive steps: (a) monitoring, reporting, and verification of carbon emissions from ships; (b) GHG reduction targets for the maritime transport sector; and (c) further measures, including market-based measures (MBM) (Nikitakos et al. 2018).

Data quality management (DQM) is one of the important tools for the effective implementation of the MRV regime in the maritime industry. In terms of integrity of data, reliability, and reduction of noise, DQM is necessary for a robust MRV framework. DQM serves to eliminating data holes and minimizing data leakage. Data holes exist, for example, in different sensors' intervals, manual human interference, and sensor breakdowns (Konovessis and Thong 2017). The importance of automation intake has to do with data quality, which has been clearly identified in this paper.

Within the DQM, maintaining data accuracy is of utmost importance for the MRV framework, affected by various attributes, for example, equipment used for data collection, availability of data, and method of analysis. During the verification process, the verifier must ensure that data accuracy is sufficient and in full compliance with relevant standards. Data accuracy checks could be performed by a "plausibility check" for fuel consumption data and other vessel activity data could be cross-checked with relevant data by the automatic identification system (AIS) (VARIFABIA 2017). Upon ensuring quality of the relevant data, minimization of data gaps generated from ships could be used by 
the verifier to perform a plausibility check to confirming the fuel consumption data. Vessels' inputs of MRV-associated data, such as engine room logbook, chief engineer's log abstract, and other dynamic data inputs have to be checked by the verifier during the certification for verification and compliance. Data gaps for an MRV system have to be assessed on three criteria: data collection process, procedure for data transformation, and details of company operational documentation and regulatory requirements of the MRV framework. As described in ISO 19030-1:2016, in order to make the DQM effective, data uncertainty needs to be checked through expert assessment of available resources and applicability on a case-by-case basis.

\section{Conclusion}

According to this new framework of environmental performance management for shipping, created by both EU and IMO, vessels should monitor fuel consumption and related emissions, distance traveled, time spent at sea, and finally loaded cargo. All these parameters provide the so-called "energy efficiency indicators"; the issue of energy efficiency is very high on the contemporary political agenda, as a rather significant number of governments around the world are focusing heavily on how to reduce wasteful energy consumption and GHG emissions. Existing maritime energy policy regimes, such as SEEMP, EEDI, and EEOI under the MARPOL Annex VI, provide a good starting point to reduce $\mathrm{CO}_{2}$ emissions from ships. The most relevant interventions culminated in the latest decision of the IMO to reduce emissions by at least $50 \%$ by 2050 , compared to the 2008 baseline of $20 \%$, at the 72 nd MEPC meeting in London, May 2018. The IMO strategy strengthens the specific focus on reduction of $\mathrm{CO}_{2}$ emissions from shipping, in line with the Paris Agreement temperature goals.

However, the SEEMP and EEOI onboard ships are still considered as insufficient and less effective. The analysis at hand explored issues related to SEEMP, EEDI, EEOI, and EU's MRV and IMO DCS. Data-related barriers to energy efficiency measures onboard ships were identified through an online survey questionnaire. The effective implementation of MRV can be influenced by several factors. A positive note was high expectation and trust in MRV as an effective policy by a vast majority of maritime stakeholders. It is a widely shared belief that the MRV framework will enhance the existing maritime energy policies. On the other hand, there are still pending questions regarding the robustness and quality of data to successfully support the various MRV tasks and necessary exchange of information. The findings show that there seems to be a gap among shipping companies in adopting quality management systems, such as ISO standards, and technological investment in their vessels is still needed.

The limitation of the current research effort was its exploratory nature with a limited number of respondents and data obtained through only one method, an online survey. As a pilot study in Singapore and Bangladesh, with participants' limited experience of working with the regulatory bodies like the EU or IMO, 
the results could provide a rather different picture. Though this is the case, many of our respondents operate their vessels in EU waters. Since the maritime business is global, they are equally sensitive to the development of maritime energy policies and the issue of compliance. In this regard, future research can investigate the views of EU-based maritime professionals and experts to compliment the research findings from this paper.

\section{Appendix 1: Sample online survey}

* Required

1. Email address *

\section{Consent}

Please check below boxes to give your consent:

2. "By completing this questionnaire, I consent to my personal data being used for this study and other research. I understand that all personal data relating to volunteers is held and processed in the strictest confidence. I understand that my participation is entirely voluntary and that I can withdraw at any time." *

Check all that apply.

$$
\text { Yes }
$$

\section{Group A: General}

3. Which one of the below groups you belong to in the shipping industry? * Mark only one oval.
Ship Managers
Ship's Engineers
Navigating officers
Other:

4. Which one of the following best describes your gender? * Check all that apply.
Male
Female
Others

5. Which one of the below age groups you belong to? * Mark only one oval.
$18-24$
25-34
$35-45$
$45+$ 
6. What is the level of your academic qualification? *

Mark only one oval.

Masters and above

Bachelor

Diploma on maritime affairs

Other:

\section{Group B: Policy Perspective}

How are the shipping companies getting ready, setting up policy and strategy, prior kicking off IMO's Data Collection System (MARPOL ANNEX-VI, Reg-22A) and EU MRV (Reg. 2015/757) System?

\section{1. Does your company operate according to the requirements and guidelines of the} International Standards, such as-?

Check all that apply.

ISO 14001: 2015 (Environmental)

ISO 50001: 2011 (Energy Management)

ISO 9001: 2015 (Quality) and

Other:

8. Is Energy Efficiency included in any of the followings in your company? Check all that apply.

The company's corporate goals and objectives

Quality Management System

Not included at all.

Other:

9. Recently, in many companies, a dedicated Energy Management Team is employed to monitor energy efficiency of the company. Does such energy department exist in your company? Mark only one oval.
Yes
Other:

No

10. As IMO's Fuel Consumption Monitoring, Reporting and Verification (MRV) System starting from 1 Jan 2019, similarly every ship entering/leaving EU, voyage and annual aggregated data for $\mathrm{CO} 2$ emission are to be reported to the Administration from 1 Jan 2018. What is the status of your company regards to implement MRV system for any of your vessel?

Check all that apply.

Ship specific Monitoring Plan Approved by Accredited Verifier

Consideration given for policy adoption

Not engaged in EU bound voyages

Not aware of such rules. 
11. In your opinion, what would be the impact of MRV on the existing Ship Energy Efficiency Management Plan (SEEMP) for energy saving in your domain?

Mark only one oval.

Will affect positively in large extent

Minor positive impact

No effect at all

Negative effect on SEEMP

\section{Group C:Technological Standpoint}

What are the existing technology gap for proper implementation of MRV process in shipping?

12. What is your view on the installation of "Real-time online fuel consumption monitoring device" to collect data from remote location as a solution for MRV process?

Mark only one oval.
It is the best solution.
It is as good as other solutions.
Not sure
It is not a good solution.
Other:

13. According to IMO and EU, there are four engine Fuel consumption measurement methods, listed as- Method-A: BDN and periodic stock takes of fuel tanks, Method-B: Bunker tanks monitoring, Method-C: Flowmeter for applicable combustion process, and Method-D: Direct CO2 emission measurement method from exhaust uptakes (For EU MRV)Please enter number in below boxes for ranking based on your preference (Most preferred=1, Least preferred=4) Mark only one oval per row.

\begin{tabular}{l} 
Method A \\
Method B \\
\hline Method C
\end{tabular}

14. What are the means of getting ship's daily dynamic data readings on your vessel? Mark only one oval.
Auto-logging with sensors (Continuous monitoring)
Manual logging (at every 24 hour)
Other:

15. In your view, what is the most important factor for improving data quality? Mark only one oval.
Improved collection procedures and management
Auditing regime
Improved automation (installing sensors)
Other: 
16. Is your ship assessed for compatibility for MRV (Retrofitting option) technology gap to meet IMO and EU requirement?

Mark only one oval.
Assessed by External MRV service provider
Assessed by Internal experts
Status not assessed
Other:

\section{Group D: Human Element}

What is the status of expertise, knowledge and awareness of ship's crew on correct data feed, monitoring, reporting and verification requirements?

17. Are you aware of the development of regulatory requirement by IMO and European Union regarding MRV process?

Mark only one oval.
$\bigcirc$ Yes
No
Other:

18. SEEMP requires the company to develop plan with specific roles and responsibilities for personnel to improve energy efficiency on board, do you have any specific role of such kind in your organization?

Mark only one oval.

$$
\begin{aligned}
& \text { Yes, designated for specific duties } \\
& \text { No } \\
& \text { Other: }
\end{aligned}
$$

19. What kind of training you or your crew receives to increase awareness, familiarity and knowledge on SEEMP/EEOI/Ship's Energy Efficiency? Check all that apply.

In-house training sessions as per SEEMP

Customized training by External experts or institution

Not participated any training about EnE

Other:

20. Robust and dynamic MRV system requires proper training and knowledge about the process, what kind of training you have received in this regard?

Check all that apply.

\section{Academic training}

On-board training by Chief Engineer

Did not receive any training

I am not part of the system 
21. MARPOL ANNEX VI, Regulation 22A: Data Collection system urges shipping companies not to increase administrative burden for crew. Do you agree that MRV regulation will not cause burden for the crew?

Mark only one oval.
Yes
No
Other:

\section{Group E: Ensuring data quality}

What are the barriers and constraints on ensuring data quality?

22. The correct data feed is the most important phase of MRV process. In your opinion what mostly causes the inaccuracy of data?

Check all that apply.

Error with the measuring device

Human error while collection and interpretation

Lack of correct procedure

Other:

23. Manual log taking, entry of data and reporting to HQ with Noon Report, this whole process of ships emission data collection consists of significant amount of error and could be eliminated by employing automated monitoring system. To what extent do you agree with the above opinion?

Mark only one oval.

Strongly disagree

Agree

Disagree

Neutral

Other:

24. In your opinion, what could be the most common cause of misreporting or wrong entry? Mark only one oval.

Fraudulent entry of data

Human error or lack of knowledge

Intentionally (Maintaining Ship's undeclared stock)

Other: 


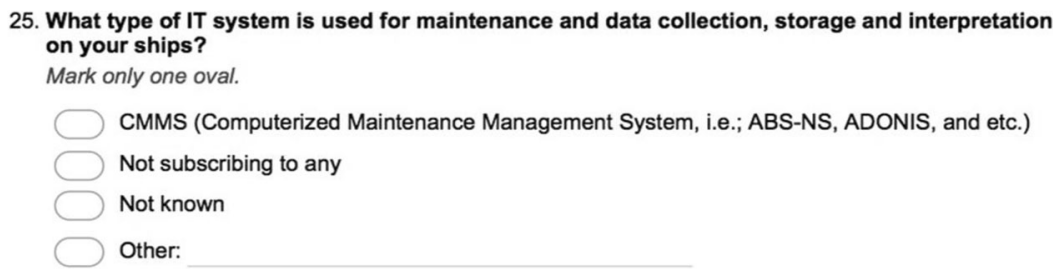

26. Does the organization identify the potential problem with the method of data collection and transformation and takes necessary steps for improvement?

Mark only one oval.

Yes

No

Other:

Publisher's note Springer Nature remains neutral with regard to jurisdictional claims in published maps and institutional affiliations.

\section{References}

Acciaro M, Hoffmann PN, Eide MS (2013) The energy efficiency gap in maritime transport. Journal of Shipping and Ocean Engineering 3:1-10

Dalaklis D, Baxevani E (2016) Arctic in the global warming phenomenon era: new maritime routes \& geopolitical tensions. In: Delfour-Samama O, Leboeuf C, Proutière-Maulion G (eds) New maritime routes: origins, evolution and prospects. A. Pedone, Paris

Dalaklis D, Baxevani E, Siousiouras P (2016) The future of arctic shipping business and the positive influence of the Polar Code, International Association of Maritime Economists 201EUR6 Conference, HamburgGermany, 24 August 2016

Dewan MH, Yaakob O, Suzana A (2018) Barriers for adoption of energy efficiency operational measures in shipping industry. WMU J Marit Aff 17:169. https://doi.org/10.1007/s13437-018-0138-3

Dillman DA (2007) Mail and internet surveys, 2nd edn. Wiley, Hoboken

DNV-GL (2018) From EU MRV to IMO DCS. Retrieved from https://www.dnvgl.com/maritime/imodcs/index.html. Accessed 3 Sept 2018

Drewniak M, Dalaklis D, Kitada M, Ölçer AI, Ballini F (2018) Geopolitics of Arctic shipping: the state of icebreakers and future needs. Polar Geogr 41(2):107-125. https://doi.org/10.1080/1088937 X.2018.1455756

EUR-Lex (n.d.) Access to European Union law. Retrieved from https://eur-lex.europa.eu/homepage.html. Accessed 3 Sept 2018

European Commission (2017) Climate action: The EU emissions trading system (EU ETS). Retrieved from https:/ec.europa.eu/clima/policies/ets_en. Accessed 3 Sept 2018

IMO (2009) Second greenhouse gas study 2014. International Maritime Organization, London

IMO (2010) The 61st MEPC information paper. International Maritime Organization, London

IMO (2015) Third greenhouse gas study 2014. International Maritime Organization, London

IPCC (2013) Climate change 2013: the physical science basis. Intergovernmental Panel for Climate Change, Geneva

ISO (2017) International organization for standardization. Retrieved from https:/www.iso.org/home.html. Accessed 3 Sept 2018

Kitada M, Ölçer AI (2015) Managing people and technology: the challenges in CSR and energy efficient shipping. Research in Transportation Business \& Management 17:36-40. https://doi.org/10.1016/j. rtbm.2015.10.002 
Konovessis D, Thong SK (2017) Smart ships - paradigm shift with data analytics. Retrieved from http://commons.wmu.se/cgi/viewcontent.cgi?article=1011\&context=marener_conference. Accessed 3 Sept 2018

Nikitakos N, Dalaklis D, Siousiouras P (2018) Real Time Awareness for MRV Data. In: Ölçer A, Kitada M, Dalaklis D, Ballini F (eds) Trends and challenges in maritime energy management. WMU Studies in Maritime Affairs, vol 6. Springer, Cham. https://doi.org/10.1007/978-3-319-74,576-3_5

Ölçer AI (2018) Introduction. In: Ölçer AI, Kitada M, Dalaklis D, Ballini F (eds) Trends and challenges in maritime energy management. WMU Studies in Maritime Affairs, vol 6. Springer, Cham. https://doi. org/10.1007/978-3-319-74,576-3 1

Ölçer AI, Ballini F (2018) Energy management in the maritime industry. In: Froholdt LL (ed) Corporate Social Responsibility in the Maritime Industry. Springer, Heidelberg, pp 131-148

Ölçer AI, Baumler R, Ballini F, Kitada M (2018) Maritime energy management. In: Visvikis I, Panayides P (eds) Shipping Operations Management. Springer, Heidelberg, pp 177-196

UN (2017) World Population Prospects: The 2017 revision, key findings and advance tables. Working Paper No. ESA/P/WP/248. Population Division, Department of Economic and Social Affairs, United Nations

Verifavia (2017) Verifavia shipping: Verify, comply, navigate. Retrieved from http://www.verifavia-shipping. com/shipping-carbon-emissionsverification/shipping-mrv-regulation-the-mrv-process-8.php. Accessed 3 Sept 2018

World Economic Forum (2016) The Global risks report 2016. Retrieved from http://wef.ch/risks2016. Accessed 3 Sept 2018

Zaman I, Pazouki K, Norman R, Younessi S, Coleman S (2017) Challenges and opportunities of big data analytics for upcoming regulations and future transformation of the shipping industry. 10th International Conference on Marine Technology, MARTEC 2016. Procedia Engineering 194:537-544 